\title{
O ciberespaço como ágora eletrônica na sociedade contemporânea
}

Ricardo Viana Velloso

Mestrando em educação, cultura e organizações sociais, pela Universidade do Estado de Minas Gerais - UEMG.

E-mail: ricardo@ufmg.br

\section{Resumo}

As interações humanas no ciberespaço revelam-no como ambiente constitutivo de uma ágora contemporânea, em que os grandes debates públicos, ou as trocas simbólicas, processam-se, na era da informação, de forma significativamente transformada. As múltiplas realizações no ambiente virtual dão-se sob a égide de valores (e afinidades) culturais, com outras interfaces, compondo redes de mobilização e troca que se sustentam pela sua diversidade intrínseca e por seu dinamismo. Resultam, assim, as realizações humanas em movimentos sociais tão antigos, na sua essência, quanto a própria humanidade, mas inovadores na forma e na dinâmica que assumem, na instauração da cibercultura como marca da contemporaneidade.

\section{Palavras-chave}

Ciberespaço. Contemporaneidade. Interações humanas. Movimentos sociais. Cibercultura.

\section{The cyberspace as an electronic agora in the contemporaneous society}

\begin{abstract}
The cyberspace is the contemporaneous agora for the human interactions, where great public debates or symbolic exchanges are significantly processed in the era of information. The multiple achievements in the virtual environment are carried out under the aegis of cultural values together with other interfaces making up nets of mobilization and exchange which are supported by their intrinsic diversity and dynamism. The human achievements take place in social movements, ancient in their essence as humankind itself, but innovating in the form and dynamics they are brought out in the establishment of cyberculture as a mark of contemporaneousness.
\end{abstract}

\section{Keywords}

Cyberspace. Contemporaneity. Human interactions. Social movements. Cyberculture.

\section{INTRODUÇÃO}

Este artigo tem por objetivo examinar o ciberespaço como ambiente que compõe a ágora eletrônica na cena contemporânea, sob a égide de novas interfaces e da cibercultura, comprometidas por outras temporalidades e territorialidades.

Perceber o ciberespaço como ágora virtual enseja e demanda revisitar conceitos atinentes às esferas pública e privada, com lastro nos estudos de Arendt (2008), que resgata tais categorias nas suas origens na Grécia, bem como sua ressignificação na modernidade, quando sua distinção secular se torna tênue, favorecendo a emergência da esfera social.

Requer ainda, à guisa de contextualização da cena contemporânea, a apropriação das considerações de Hobsbawm (2006) acerca do "Breve século XX" e das incertezas que advêm da insuficiência da ciência e da técnica para fazer frente aos desafios hodiernos, dentre os quais se destacam o demográfico e o ambiental.

Para subsidiar o presente estudo, é também relevante retomar com Lévy (1993) categorias como espaço virtual, cibercultura, tecnologias da inteligência e ecologias cognitivas, que emergem no ambiente descentrado, atópico e desterritorializado da rede mundial de inter(ações) instaurada pelas tecnologias da informação e da comunicação. Vale igualmente revisitar as considerações de Johnson (2001) sobre a cultura da interface, que conferem mais amplas conotações às tecnologias na atualidade, em um contexto de interação entre tecnologia, cultura e arte, assim como os estudos de Castells (2003) e Moraes (2001) acerca da Internet na sociedade hodierna.

Há de se ressaltar que o presente artigo cuidará de abordar o ciberespaço como ambiente das ações e interações dos sujeitos sociais organizados, sob a percepção de que as redes que se compõem na sociedade não reinventam, na sua essência, os movimentos sociais, mas certamente lhes conferem outras dimensões culturais, sustentadas pela diversidade e amplitude das conexões ensejadas pelas tecnologias da informação e da comunicação, determinantes para a instauração da (ciber)cultura contemporânea. 


\section{DIMENSÕES PÚBLICA E PRIVADA DAS INTERAÇÕES HUMANAS: ORIGENS E RESSIGNIFICAÇÃO}

Retomando as origens da vida humana em sociedade, é imperativo reconhecer, inicialmente, duas esferas de interações: a esfera privada, em cujo âmbito as realizações se identificam com o atendimento a necessidades biológicas, quais sejam a sobrevivência e a perpetuação da vida; e a esfera pública, lugar de interações que extrapolam essa condição natural mais imediata em busca da liberdade no próprio mundo, comum aos homens que buscam, nessa seara, efetiva visibilidade. Tais instâncias, marcadas por flagrante antinomia, remetem à consideração das categorias labor, trabalho e ação, tratadas por Arendt em A condição humana ${ }^{1}$.

A autora situa o labor como atividade inerente à natureza humana identificada com a necessidade de preservação da vida. Assim é que, na divisão clássica da atividade humana, ao homem é reservado o mister de prover o alimento e a segurança, enquanto à mulher se reserva a reprodução. O trabalho, por sua vez, extrapolando a circunscrição do natural, coloca o homem no exercício da criação de coisas artificiais, revelando o homo faber. Por fim, tem-se a ação, que é apresentada pela autora como outra atividade humana, cuja realização demanda (e enseja) um ambiente de interações com outros homens, de forma contínua. Por seu caráter eminentemente interacional, a ação pode então ser distinguida das categorias labor e trabalho em virtude de a primeira se comprometer com a esfera pública, enquanto as demais se situam originariamente, conforme esposado por Arendt (2008), na esfera privada.

Contrapondo características e funções, em virtude das interações perpetradas em seu âmbito e dos seus diferentes componentes motivadores, as esferas pública e privada definem ambientes dicotômicos das realizações humanas.

Assim é que a esfera da casa (oikos) corresponde ao lugar da vida privada, comprometida com as demandas naturais da existência humana. E, como observa Arendt (2008, p.40),

\footnotetext{
${ }^{1}$ ARENDT, Hannah. A condição humana. Tradução de Roberto Raposo. Rio de Janeiro: Forense universitária, 2008. Publicada em 1958, a obra suscita muitas questões acerca das realizações humanas ao longo da história, sendo relevantes na presente abordagem as considerações da autora sobre o público e o privado, bem como sua ressignificação na modernidade, esferas cuja apreciação demanda a apreensão das categorias labor, trabalho e ação, constitutivas da existência humana.
}

O fato de que a manutenção individual fosse a tarefa do homem e a sobrevivência da espécie fosse a tarefa da mulher era tido como óbvio; e ambas estas funções naturais, o labor do homem no suprimento de alimentos e o labor da mulher no parto, eram sujeitas à mesma premência de vida.

Já a esfera pública, reconhecida como o lugar do comum, revela-se como o palco das interações e possível âmbito do exercício da liberdade, levada a efeito na ágora grega, a praça dos debates e das manifestações públicas; liberdade que, na esfera privada, não se dá em virtude das relações desiguais e do reino da necessidade e das carências biológicas, já referidas. Nesse diapasão, a esfera pública constitui o lugar dos cidadãos livres e iguais, no exercício da ação, para além do labor e do trabalho. Destaca Arendt (2008) que, na esfera do público, diferentemente do que se dá na esfera privada com o recurso à força, o que se tem é a hegemonia do discurso, da persuasão.

A busca pela visibilidade (e pela liberdade) na cena pública, que redimensiona a existência humana, balizada na ação, faz emergir, no curso da história, outra dimensão das interações, qual seja, a esfera social. Esse fenômeno se processa em um movimento de complexidade, trazendo a público temas até então adstritos ao ambiente privado. O divisor de águas entre o público e o privado, instâncias até então circunscritas à antinomia de suas relações, vai se fazendo tênue, o que promove o recrudescimento dessa esfera emergente, de cunho social. Trata-se de uma instância que, surgida no início da era moderna, não equivale ao público nem ao privado.

O cenário que se desenha com a emergência da esfera social reflete-se concomitantemente ao surgimento do estado nacional, revelando o setor público-estatal, o setor privado e, de forma cada vez mais pronunciada, o terceiro setor $^{2}$, com caráter também público, mas não-estatal, envolvendo a participação de voluntários em busca de processos e resultados identificados com o bem-estar social.

\section{CONTEMPORANEIDADE E INCERTEZAS}

A par da instauração das instâncias de realizações humanas, movidas ora pela necessidade, ora pelo desejo de liberdade, sob a égide do labor, do trabalho e ou da

\footnotetext{
2 Por decorrer da associação do caráter público (não estatal) aliado à iniciativa privada (sem fins lucrativos), esse setor ganha projeção e relevo progressivo por se inserir nos espaços ou lacunas gerados pela ineficiência ou ausência do Estado.
} 
ação, a sociedade se conduz e se redesenha historicamente, compondo, na modernidade, um cenário de encantamento com a razão. A aventura humana, contudo, revela-se marcada por conquistas que se alternam com percalços, traduzindo-se em um flagrante paradoxo, cujo exercício de compreensão remete aos estudos de Hobsbawm (2006) acerca do "Breve século XX", ou a Era dos Extremos um lapso de tempo entre 1914 e 1991, intervalo histórico que abriga concomitantemente avanços científicos e tecnológicos e guerras, destruição e desigualdade.

Hobsbawm (2006) identifica como "Era da Catástrofe" o período de 1914 até depois da Segunda Guerra Mundial. Essa fase é sucedida por "cerca de 25 ou 30 anos de extraordinário crescimento econômico e transformação social, anos que provavelmente mudaram de maneira mais profunda a sociedade humana que qualquer outro período de brevidade comparável" (HOBSBAWM, 2006, p.15), constituindo-se na "Era do Ouro". Sucedendo esse recorte temporal, a humanidade experimenta, segundo o autor, uma era de incertezas e crises.

O século XX, além de seus paradoxos, revela uma nova temporalidade, traduzida na ausência de nexos articuladores com o passado e na falta de um sentido prospectivo, instaurando-se, então, uma espécie de "presente contínuo", que traz no bojo desse fenômeno a mudança (ou perda) de paradigmas de relacionamento social e humano. A hipertrofia do sentido da razão encontra, com relevo cada vez mais expressivo, uma insuficiência como resposta às angústias e às indagações de seu tempo, em grande parte porque divorciadas da percepção sensorial e do senso comum, com os quais estabelece relação eminentemente dicotômica.

Pronuncia-se aí um novo desencantamento, a exemplo do que se deu com relação à fé, quando da transcendência para a modernidade.

O Breve Século XX acabou em problemas para os quais ninguém tinha, nem dizia ter, soluções. Enquanto tateavam o caminho para o terceiro milênio em meio ao nevoeiro global que os cercava, os cidadãos do fin-de-siècle só sabiam ao certo que acabara uma era da história. E muito pouco mais (HOBSBAWM, 2006, p. 537).

O século XX deixa, então, nessa perspectiva, o legado da incerteza.

Ci. Inf., Brasília, v. 37, n. 2, p. 103-109, maio/ago. 2008
Ademais, é o momento histórico que experimenta em mais larga escala, no bojo do progresso tecnológico atinente aos transportes e às telecomunicações, o processo de globalização

cada vez mais acelerado e a incapacidade conjunta de as instituições públicas e de o comportamento coletivo dos seres humanos se acomodarem a ele (HOBSBAWM, 2006, p. 24).

A aldeia global ${ }^{3}$ que se configura no contexto da modernidade não constitui, como se poderia supor, a quebra de fronteiras seguida de progressiva conquista da igualdade. Diferentemente disso, o que se tem, com a acentuação das desigualdades, é,

num mundo cada vez mais globalizado, o fato mesmo de as ciências naturais falarem uma única língua universal e operarem sob uma única metodologia (HOBSBAWM, 2006, p.506)

Sobre o presente cenário, em que se dão movimentos de mudialização sobretudo de cunho econômico, é Antônio (2002, p.100) quem observa que

a globalização não tem sentido verdadeiramente cosmopolita nem universalista: um vasto e poderoso domínio de capitais e mercados e de tecnologias de informação e comunicação faz com que se beba o mesmo refrigerante e se coma o mesmo sanduíche e se assista aos mesmos filmes e aos mesmos programas televisivos e aos mesmos esquemas de marketing nos quatro cantos do mundo.

O fato é que os paradoxos e as incertezas presentes na cena contemporânea marcam-na com outras temporalidades e territorialidades, potencializadas pelo advento das tecnologias da informação e da comunicação, alavancadas pelo desenvolvimento da informática, que enseja (e impõe) novas concepções e referências à dinâmica do tempo e do espaço.

Relativamente ao redesenho do espaço das interações humanas, emergem teses identificadas com o fim dos territórios, que, diferentemente de se confirmarem, revelam, antes, outras territorializações, as quais, segundo Haesbaert (2004), traduzem-se na redefinição dos

${ }^{3} \mathrm{O}$ termo é cunhado por Marshall Mc Luhan, sociólogo canadense, para se referir às novas configurações assumidas pelas interações entre os diversos países (e culturas), superando a linearidade e os limites territoriais e temporais clássicos, situação que, na tese do autor, colocaria o mundo no patamar de uma aldeia, no âmbito da qual perseveram as desigualdades. 
espaços, que passam a incorporar dimensões materiais e ou simbólicas. Desse movimento, resultam territórios físicos, virtuais, políticos e culturais, dentre outros, possibilitando a vivência de multiterritorialidades, em um contexto em que se permite

(...) pela comunicação instantânea, contatar e mesmo agir sobre territórios completamente distintos do nosso, sem a necessidade de mobilidade física. Tratase de uma multiterritorialidade envolvida nos diferentes graus daquilo que poderíamos denominar como sendo a conectividade e/ou vulnerabilidade informacional (ou virtual) dos territórios. (HAESBAERT, 2004, p.345)

As condutas e relações sociais e humanas que se dão na circunscrição desses territórios emergentes, em particular do território virtual, convidam ao exame de seu significado e do caráter que assumem, bem como das variáveis com que estão imbricadas, para sua melhor compreensão e, por extensão, para que se possa tratar a sua ressituação no ciberespaço. Essa categoria, por sua vez, reclama exame mais detido, de forma a favorecer a compreensão das interações humanas em seu âmbito, sob múltiplas configurações.

\section{CIBERESPAÇO: OUTRO AMBIENTE DAS REALIZAÇÕES HUMANAS}

O espaço virtual, imbricado com outras temporalidades e outras territorialidades, destaca-se pela celeridade das informações hipertextuais, dispostas em rede, as quais possibilitam leituras mais imediatistas pela associação da expressão verbal a imagens e sons entre outros; mas ensejam também leituras extensivas, caminhos alternativos para o leitor que, valendo-se dos nós na rede hipertextual não-linear, vê-se co-autor, em um exercício autônomo de produção de sentido da malha textual. Em muitas situações, as temporalidades são também redimensionadas por atualizações contínuas e quase simultâneas aos fatos, às notícias, aos múltiplos registros na Internet.

E, como observa Marcuschi (2005, p.13),

em certo sentido, pode-se dizer que, na atual sociedade da informação, a Internet é uma espécie de protótipo de novas formas de comportamento comunicativo.

Embora o autor se atenha às situações comunicativas, é possível estender o olhar às situações mais amplas de relações sociais, já que a comunicação constitui ato e processo social que comporta relações de poder e trocas simbólicas de amplo espectro, insertas no cenário constitutivo de uma cibercultura.

Nesse contexto, novas territorialidades também se revelam, na medida em que os contornos têm seu foco descolado da materialidade, trazendo como marcas preponderantes as dimensões simbólicas. Tem-se, então, outros territórios em que se processam novas experiências, imbricadas com múltiplas interfaces. Nesses territórios, as fronteiras se diluem, instaurando uma nova geografia. A ausência de marcos espaço-temporais rígidos, substituída por nós de conhecimento e de aglutinação motivacional, ensejam contínua mobilidade ou nomadismo, sobre o qual considera Lévy:

O espaço do novo nomadismo não é o território geográfico nem o das instituições ou dos Estados, mas um espaço invisível dos conhecimentos, dos saberes, das forças de pensamento no seio da qual se manifestam e se alteram as qualidades do ser, os modos de fazer sociedade. Não os organismos do poder, nem as fronteiras disciplinares, nem as estatísticas dos mercados, mas sim o espaço qualitativo, dinâmico, vivo, da humanidade que se inventa ao mesmo tempo que produz o seu mundo (LÉVY, 1997, p.17).

Desse movimento emergem territórios cognitivos coletivizados, em que se inserem autores e leitores investidos da condição de co-autores que produzem permanentemente sentidos na interação com as malhas textuais, compostas a partir dos hipertextos ${ }^{4}$, constitutivos das ecologias cognitivas.

É fato que, de um lado, territórios se podem conceber com certo grau de anonimato, como se dá, por exemplo, nas diversas salas de bate-papo em que os interlocutores usam apelidos, os nicks, que ora os revelam (e as suas intenções comunicativas), ora os ocultam. De outro, todavia, concebem-se ambientes de cooperação, como as listas de discussão, os fóruns temáticos virtuais e outros, em que os interlocutores podem se inserir, em muitos dos casos, devidamente identificados, empreendendo a interação e a colaboração.

\footnotetext{
${ }^{4}$ Os hipertextos invocam uma concepção textual aberta, não-linear, que reclama novos comportamentos na sua produção de sentido, na relação com a autoria, portanto novos agenciamentos em rede relacional com outras configurações. Afinal, como esclarece Coscarelli, "o hipertexto é, grosso modo, um texto que traz conexões, chamadas links, com outros textos que, por sua vez, se conectam a outros, e assim por diante, formando uma grande rede de textos" (COSCARELLI, 2003, p.73).
} 
Nessas territorialidades em que se sobrepõem as dimensões simbólicas às materiais, situações antagônicas tendem a se definir em territorializações que se processam sob a égide do relativo anonimato, ou da deliberada identificação dos sujeitos sociais que vivenciam a coletivização de seu pensar (e fazer) em cenários de interação e ou cooperação, constituindo outras ecologias cognitivas. Trata-se de ambientes de relações que, para além da seara cognitiva, envolvem variáveis conceituais, axiológicas, estéticas e afetivas, dentre outras. Afinal, como observa Lévy,

A informática não intervém apenas na ecologia cognitiva, mas também nos processos de subjetivação individuais e coletivos. Algumas pessoas ou grupos construíram uma parte de suas vidas ao redor de sistemas de troca de mensagens (BBS), de certos programas de ajuda à criação musical ou gráfica, da programação ou da pirataria nas redes. Mesmo sem ser pirata ou hacker, é possível que alguém se deixe seduzir pelos dispositivos de informática. Há toda uma dimensão estética ou artística na concepção das máquinas ou dos programas, aquela que suscita o envolvimento emocional, estimula o desejo de explorar novos territórios existenciais e cognitivos, conecta o computador a movimentos culturais, revoltas, sonhos (LÉVY, 1993, p. 56).

Nesse contexto, pronunciam-se, no bojo de uma nova cultura, ou da cibercultura, processos de interação e de interlocução os quais compõem espaços (ou territórios) virtuais que trazem à cena conexões mais amplas e maior dinamismo, presentes nos movimentos sociais em rede, que se identificam, constituem-se e alimentam-se, dentre outros, por valores culturais, revelando-se, inclusive, como registra Castells (2003 p.115), em militâncias ambientais, feministas, pelos direitos humanos e dos ativistas ligados a um sem-número de projetos culturais e causas políticas. Nessa perspectiva,

o ciberespaço tornou-se uma ágora eletrônica global em que a diversidade da divergência humana explode em uma cacofonia de sotaques.

\section{CIBERCULTURA E OUTRAS INTERFACES}

A relação entre o usuário e o computador implica interfaces que se dão através de softwares que medeiam as interações entre ambos. Nesse exercício interativo, segundo Johnson (2001), instauram-se novos olhares, novas percepções e novas concepções para com o mundo, o que redunda em outras posturas e condutas humanas ante os sujeitos e a sociedade propriamente dita, já que "a relação governada pela interface é uma relação semântica, caracterizada por significado e expressão, não por força física." (JOHNSON, 2001, p.17).

Apresentam-se as interfaces tão intrigantes quanto sedutoras, possibilitando até a aproximação entre categorias aparentemente antinômicas, como tecnologia e arte e, ainda com Johnson (2001, p. 174), é possível asseverar que

Nossas interfaces são histórias que contamos para nós mesmos para afastar a falta de sentido, palácios de memória construídos de silício e luz. Elas vão continuar a transformar o modo como imaginamos a informação, e ao fazê-lo irão nos transformar também - para melhor e para pior.

Envolvidos nesse contexto de múltiplas interações comprometidas com dimensões simbólicas, marcadas pela instantaneidade e transitoriedade, pelo descentramento e pela atopia, os sujeitos sociais se vêem constituindo e vivenciando a cibercultura, cujo universo

não possui nem centro nem linha diretriz. É vazio, sem conteúdo particular. Ou antes, ele os aceita todos, pois se contenta em colocar em contato um ponto qualquer com qualquer outro, seja qual for a carga semântica das entidades relacionadas. (LÉVY, 2005, p. 11).

O ambiente instaurado enseja a retomada de antigas interações e mobilizações de atores e grupos sociais agora com novos contornos temporais e territoriais, à medida que as informações (e as trocas) se dão com maior volume e celeridade, além de prescindirem de contornos territoriais físicos. Desse processo, emerge, de forma alternada, a sucessão de ações locais e globais, compondo, dentre outros, o movimento contemporâneo da cibermilitância, que se dá no bojo das organizações em rede. Segundo Castells,

os movimentos sociais do século XXI, ações coletivas deliberadas que visam a transformação de valores e instituições da sociedade, manifestam-se na e pela Internet. $\mathrm{O}$ mesmo pode ser dito do movimento ambiental, o movimento das mulheres, vários movimentos pelos direitos humanos, movimentos de identidade étnica, movimentos religiosos, movimentos nacionalistas e dos defensores/ proponentes de uma lista infindável de projetos culturais e causas políticas. (CASTELLS, 2003, p. 114). 
À guisa de exemplo, podem-se registrar com Moraes (2001) alguns segmentos da sociedade civil que, mobilizados por mais diversos temas e interesses, investem no ciberespaço como forma de ampliar suas articulações e interlocuções e de dar visibilidade às suas causas, dentre eles, o Movimento dos Trabalhadores Rurais Sem-Terra (MST), a Central Única dos Trabalhadores (CUT), a Conferência Nacional dos Bispos do Brasil (CNBB), a Ordem dos Advogados do Brasil (OAB), o Instituto Brasileiro de Defesa do Consumidor (IDEC) e o Médico Sem Fronteiras.

Nesse diapasão, as interações humanas e suas realizações, inicialmente movidas pelo labor, sob a ótica de Arendt, e em seguida pelo trabalho e finalmente pela ação, ganham novos contornos e uma dinâmica diferenciada.

O cenário virtual, ou o ciberespaço, passa a se constituir em importante território da esfera social, a ágora ${ }^{5}$ eletrônica contemporânea, que possibilita dar visibilidade aos fatos da vida privada, tratar fatos e fenômenos da esfera pública e sobretudo redimensionar a esfera social. Por seu descentramento e atopia, como já referido, enseja diluir as concentrações de poder e ampliar a participação dos atores sociais e a projeção dos diversos segmentos. Todavia, como adverte Castells,

na co-evolução da Internet e da sociedade, a dimensão política de nossas vidas está sendo profundamente transformada. $O$ poder é exercido antes de tudo em torno da produção e difusão de nós culturais e conteúdos de informação. $\mathrm{O}$ controle sobre redes de comunicação torna-se a alavanca pela qual interesses e valores são transformados em normas condutoras de comportamento humano. Esse movimento se processa, como em contextos históricos anteriores, de maneira contraditória. A Internet não é um instrumento de liberdade, nem tampouco a arma de dominação unilateral (CASTELLS, 2003, p. 135).

Em síntese, o ciberespaço não se constitui, por si mesmo, em garantia de conquista de democracia, igualdade e ou liberdade. É inconteste que, não obstantes os novos parâmetros temporais e territoriais, persistem as desiguais correlações de força; não apenas de caráter físico, como se viu na esfera privada na Grécia Antiga, nem tampouco de caráter retórico, como se assistiu na esfera pública em que a palavra assumia o papel de se pôr a serviço da

5 Sendo, na Antigüidade Clássica, a praça principal da polis grega, a ágora é tomada aqui como o espaço das interações (virtuais) na esfera pública, dos debates políticos, da convivência e da visibilidade, sendo, assim, o espaço da cidadania. persuasão; mas de caráter simbólico em uma acepção mais ampla, uma vez que as interações se dão em ambiente diverso do que historicamente se teve. Em contrapartida, as interações em outra cena, com novas interfaces e com carga simbólica redimensionada, colocam as realizações humanas diante de novos desafios e possibilidades.

\section{CONSIDERAC̣ÕES FINAIS}

É fato que as interações humanas, que se deram historicamente nas esferas do público e do privado, ganham novos contornos temporais e territoriais possibilitados pelas tecnologias da informação e da comunicação, que interconectam atores e segmentos sociais de todos os cantos, na era da informação. Tais interações envolvem, para além das referências materiais clássicas, dimensões simbólicas, as quais são suscitadas tanto pelas interfaces entre o homem e o computador quanto pelas trocas virtuais entre as culturas geradoras de diferentes perspectivas, anseios e valores.

Como lembra Johnson (2003, p.24),

a interface já alterou o modo como usamos computadores e vai continuar a alterá-lo nos anos vindouros. Mas está fadada a mudar outros domínios da experiência contemporânea de maneiras mais improváveis, mais imprevisíveis.

As interações multiculturais, por sua vez, compondo a cibercultura pelas trocas simbólicas no ciberespaço, resultam nos contornos da ágora eletrônica em que se processam as manifestações do público e do privado e múltiplos exercícios de expressão que dão visibilidade aos sujeitos e segmentos sociais. Em um contexto de descentramento, de atopia, flexibilidade e dinamismo, emergem múltiplas vozes, compondo a "cacofonia" referida por Castells (2003), como expressão do exercício interacionista na esfera social da contemporaneidade.

O cenário das interações ciberespaciais, ou a ágora eletrônica, embora constituindo-se com novos contornos temporais e territoriais em que se processam as trocas simbólicas, não tem o condão de, por si só, instaurar uma nova correlação de forças. Afinal, o que há de definir na ágora virtual, assim como se deu na ágora grega, as interações humanas e seus rumos, é a correlação de forças, que, hodiernamente, para além do embate retórico referido por Arendt (2008), haverá de envolver as novas interfaces e as trocas simbólicas. 
Por fim, ainda que repelindo a percepção ingênua de que a ágora eletrônica poderia reorientar as relações de poder e troca, é possível asseverar que o novo ambiente instaurado suscita novos desafios e outras possibilidades para as interações humanas e, em última análise, para os sujeitos sociais.

Artigo submetido em 25/10/2008 e aceito em 22/12/2008.

\section{REFERÊNCIAS}

ANTÔNIO, Severino. Educação e transdisciplinaridade: crise e reencantamento da aprendizagem. Rio de Janeiro: Lucerna, 2002.

CASTELLS, Manuel. A galáxia da Internet: reflexões sobre a internet, os negócios e a sociedade. Tradução Maria Luiza X. de A. Borges; revisão Paulo Vaz. Rio de Janeiro: Jorge Zahar, 2003.

COSCARELLI, Carla Viana. Entre textos e hipertextos. In: COSCARELLI, Carla Viana (Org.). Novas tecnologias, novos textos, novas formas de pensar. Belo Horizonte: Autêntica, 2003.

HAESBAERT, R. O mito da desterritorialização: do "fim dos territórios" à multi-territorialidade. Rio de Janeiro: Bertrand Brasil, 2004.
HANNAH, Arendt. A condição humana. Tradução de Roberto Raposo. Rio de Janeiro: Forense universitária, 2008.

HOBSBAWM, Eric J. Era dos extremos: o breve século XX: $1914-1991$. Tradução Marcos Santarrita. São Paulo: Companhia das Letras, 2006.

JOHNSON, Steven. Cultura da interface: como o computador transforma nossa maneira de criar e comunicar. Rio de Janeiro: Jorge Zahar, 2001.

LÉVY, Pierre. As tecnologias da inteligência: o futuro do pensamento na era da informática. Rio de Janeiro: Editora 34, 1993.

A inteligência coletiva: por uma antropologia do ciberespaço. 3. ed. São Paulo: Loyola, 1997.

Cibercultura. Tradução de Carlos Irineu da Costa. São Paulo: Editora 34, 2005.

MARCUSCHI, Luiz Antônio. Gêneros textuais emergentes no contexto da tecnologia digital. In: _-_-_-_; XAVIER, Antônio Carlos (Org.). Hipertextos e gêneros digitais: novas formas de construção de sentido. Rio de Janeiro: Lucerna, 2005.

MORAES, Denis de. O concreto e o virtual: mídia, cultura e tecnologia. Rio de Janeiro: DP\&A, 2001. 